\title{
PENERAPAN ARTIFICIAL NEURAL NETWORK DENGAN OPTIMASI MODIFIED ARTIFICIAL BEE COLONY UNTUK MERAMALKAN HARGA BITCOIN TERHADAP RUPIAH
}

\author{
Di Mokhammad Hakim Ilmawan' 1 , Budi Warsito², Sugito ${ }^{3}$ \\ 1,2,3 Departemen Statistika, Fakultas Sains dan Matematika, Universitas Diponegoro \\ e-mail : kim.ilmawan@gmail.com
}

\begin{abstract}
Bitcoin is one of digital as sets that can be used to make a profit. One of the ways to use Bitcoin profitly is to trade Bitcoin. At trade activities, decisions making whether to buy or not are very crucial. If we can predict the price of Bitcoin in the future period, we can make a decisions whether to buy Bitcoin or not. Artificial Neural Network can be used to predict Bitcoin price data which is time series data. There are many learning algorithm in Artificial Neural Network, Modified Artificial Bee Colony is one of optimization algorithm that used to solve the optimal weight of Artificial Neural Network. In this study, the Bitcoin exchage rate against Rupiah starting September 1,2017 to January 4, 2019 are used. Based on the training results obtained that MAPEvalue is 3,12\% and the testing results obtained that MAPEvalue is 2,02\%. This represent that the prediction results from Artificial Neural Network optimized by Modified Artificial Bee Colony algorithm are quite accurate because of small MAPE value.
\end{abstract}

Keywords: Bitcoin, predict, time series, Artificial Neural Network, Modified Artificial Bee Colony

\section{PENDAHULUAN}

Cryptocurrency menjadi perhatian dunia pada akhir tahun 2017 karena Bitcoin merupakan salah satu mata uang kripto yang nilai tukarnya lebih dari 250 juta rupiah untuk satu keping Bitcoin. Menurut Wijaya (2018) perbedaan utama antara mata uang kripto dengan mata uang virtual terletak pada metode kontrol. Bitcoin dapat digunakan sebagai aset untuk meraih keuntungan dengan menggunakan konsep Trading mata uang.

Trading dalam bahasa Inggris artinya adalah melakukan pertukaran barang atau jasa dari satu pihak ke pihak yang lain. Rekam nilai tukar Bitcoin terekam tiap harinya sehingga hal tersebut merupakan suatu peluang yang dapat digunakan untuk membuat pemodelan runtun waktu yang dapat digunakan sebagai bahan pertimbangan untuk melakukan aktivitas Trading Bitcoin. Kompleksnya data runtun waktu Bitcoin disebabkan harganya yang fluktuatif membuat metode-metode analisis runtun waktu konvensional seperti ARIMA ataupun sejenisnya akan sangat sulit mendapatkan model yang tepat. Hal tersebut disebabkan terdapat asumsi-asumsi yang tidak dapat dipenuhi. Peramalan data runtun waktu menggunakan Artificial Neural Network (ANN) dapat digunakan dikarenakan ANN merupakan suatu sistem pemroses informasi yang memiliki karakteristik mirip dengan jaringan syaraf pada makhluk hidup (Warsito, 2009).

ANN dapat menyimpan informasi-informasi yang ada untuk dijadikan sebagai pengalaman dan disimpan untuk dijadikan hal yang bermanfaat. ANN diharapkan bisa beradaptasi dengan data runtun waktu harga Bitcoin yang fluktuatif dan melakukan pembelajaran sehingga dapat meramalkan nilai tukar Bitcoin di periode ke depan. Artificial Bee Colony mempunyai kelebihan dari metode metaheuristik lain seperti Particle Swarm Optimization yaitu penggunaan parameter kontrol yang lebih sedikit (Karaboga \& Akay, 2009). Modifikasi algoritma ABC dapat memberikan performa konvergensi yang lebih baik jika dibandingkan dengan algoritma ABC biasa (Shahrudin \& Mahmudin, 2014). Penelitian yang dilakukan Shahrudin dan Mahmudin menunjukkan bahwa berapapun nilai yang dipakai pada simulasi penelitian tersebut hasilnya selalu modifikasi algoritma ABC lebih baik daripada algoritma ABC. Modified ArtificialBee Colony sebagaimetode pembelajaran ANN 
diharapkan akan meningkatkan kecepatan dalam pencarian solusi serta mendapatkan hasil pemodelan yang lebih baik dari metode pembelajaran berbasiskan gradien.

\section{TINJAUAN PUSTAKA}

\subsection{Peramalan}

Peramalan adalah salah satu unsur yang sangat penting dalam pengambilan keputusan, sebab efektif atau tidak suatu keputusan umumnya tergantung pada beberapa faktor yang tidak dapat dilihat pada saat keputusan diambil (Soejoeti, 1987). Peramalan bertujuan mendapatkan peramalan (forecast) yang dapat meminimumkan kesalahan meramal (forecast error) yang biasanya diukur dengan MSE (Mean Square Error), MAE (Mean Absolute Error), dan sebagainya (Subagyo, 1986).

\subsection{Analisis Runtun Waktu}

Runtun waktu merupakan rangkaian pengamatan kuantitatif yang diatur dalam urutan kronologis. Tujuan metode peramalan runtun waktu adalah menemukan pola dalam deret data historis dan mengekstrapolasikan pola tersebut ke masa yang akan datang (Makridakis, et al., 1999). Untuk memilih metode runtun waktu harus mempertimbangkan jenis pola data. Pola data dibedakan menjadi empat, yaitu:

1. Pola horisontal, terjadi apabila nilai data berfluktuasi di sekitar rata-rata yang tetap atau dengan kata lain stasioner terhadap rata-rata.

2. Pola musiman, terjadi apabila suatu runtun waktu dipengaruhi oleh faktor musiman, misalnya harian, bulanan, atau tahunan.

3. Pola siklis, terjadi apabila datanya dipengaruhi oleh flutuasi ekonomi jangka panjang.

4. Pola trend, terjadi apabila terdapat kenaikan atau penurunan sekuler jangka panjang dalam data

\subsection{Artificial Neural Network}

Salah satu metode peramalan yang menggunakan konsep kecerdasan buatan adalah Artificial Neural Network (ANN). ANN merupakan sistem pemroses informasi yang memiliki karakteristik mirip dengan jaringan syaraf pada makhluk hidup (Warsito, 2009). Karakteristik dari model neural network menurut Warsito (2009) antara lain:

1. Memiliki kemampuan menghasilkan output terhadap pola yang belum pernah dipelajari (generalization)

2. Memiliki kemampuan untuk memproses input yang terdapat kesalahan di dalamnya dengan tingkat toleransi tertentu

3. Mampu beradaptasi dengan perubahan yang terjadi terhadap nilai-nilai input dan output. Bentuk adaptasi ini diwujudkan dalam perubahan nilai bobot

\subsection{Artificial Bee Colony}

Artificial Bee Colony merupakan suatu algoritma optimasi yang mengadopsi dari kebiasaan eksplorasi lebah untuk mencari solusi optimal, yaitu kebiasan dalam mencari makanan dari sekelompok lebah. Algoritma Artificial Bee Colony (ABC) dikembangkan oleh Dervis Karaboga pada tahun 2005. Kinerja dari ABC memiliki kualitas yang lebih baik atau setara dengan algoritma swarm lain seperti Genetic Algorithm, Particle Swarm Optimization, Differential Evolution, dan Evolution Strategies dengan keuntungan penggunaan parameter kontrol yang lebih sedikit (Karaboga \& Akay, 2009). Langkahlangkah utama dari algoritma ABC adalah sebagai berikut:

- Inisialisasi populasi menggunakan $x_{i j}=x_{\min j}+\operatorname{rand}(0,1)\left(x_{\operatorname{maxj}}-x_{\operatorname{minj}}\right)$

- Evaluasi populasi 
- $\quad$ Tentukan iterasi $=1$

- Pengulangan

a. Untuk tahapan lebah pekerja:

1. Hasilkan solusi baru menggunakan $v_{i j}=x_{i j}+\phi_{i j}\left(x_{i j}-x_{k j}\right)$

2. Tentukan fitness dari solusi menggunakan fitness $_{i}=\frac{1}{M S E}$

3. Bandingkan $v_{i}$ dan $x_{i}$

4. Tentukan probabilitas menggunakan $p_{i}=\frac{\text { fitness }_{i}}{\sum_{n=1}^{S N} \text { fitness }_{i}}$

b. Untuk tahapan lebah penjaga:

1. Pilih solusi $x_{i j}$ berdasarkan $p_{i}$

2. Hasilkan $v_{i}$ yang baru

3. Tentukan fitness dari solusi menggunakan fitness $_{i}=\frac{1}{M S E}$

4. Bandingkan $v_{i j}$ dan $x_{i j}$

c. Untuk tahapan lebah pengintai:

Jika ada solusi yang ditinggalkan, ganti dengan menghasilkan solusi $x_{i}$ baru secara acak menggunakan $v_{i j}=x_{i j}+\phi_{i j}\left(x_{i j}-x_{k j}\right)$

d. Ingat solusi terbaik

e. Tambahkan iterasi dengan 1 , iterasi $=$ iterasi +1

Sampai persyaratan terpenuhi atau iterasi $=$ iterasi maksimum

\subsection{Modified Artificial Bee Colony}

Modifikasi algoritma $\mathrm{ABC}$ memberikan performa konvergensi yang lebih baik jika dibandingkan dengan algoritma ABC biasa (Shahrudin \& Mahmudin, 2014). Modifikasi yang dilakukan adalah pada formula $\mathrm{ABC}$ sebagai berikut:

$$
v_{i j}=x_{i j}+\phi_{i j}\left(x_{i j}-x_{k j}\right)+\varphi_{i j}\left(y_{j}-x_{i j}\right)
$$

dengan $\varphi_{i j}$ merupakan angka random berdistribusi uniform dalam rentang 0 sampai dengan 1,5 sedangkan $y_{j}$ adalah elemen ke j dari solusi global terbaik. Formula terinspirasi dari mekanisme pencarian algoritma Particle Swarm Optimization (PSO) dan digunakan untuk memperbaiki tingkat konvergensi dari algoritma PSO. Selain itu formula probabilitas solusi juga diubah menjadi:

dengan $\rho=2,5$.

$$
p_{i}=\exp \left(-\frac{1}{\rho} \text { fitness }_{i}\right)
$$

Pada penelitian yang dilakukan Shahrudin dan Mahmudin menunjukkan bahwa berapapun nilai yang dipakai pada simulasi penelitian tersebut menghasilkan kesimpulan MABC lebih baik daripada ABC.

\section{METODE PENELITIAN}

\subsection{Jenis dan Sumber Data}

Data yang digunakan pada penelitian ini adalah data sekunder, yaitu data harga 1 keping Bitcoin terhadap Rupiah dalam 2 tahun terakhir, terhitung dari tanggal 1 September 2017 hingga 4 Januari 2019. Data tersebut diperoleh dari website https://www.investing.com/. 


\subsection{Diagram Alir Analisis}

Langkah-langkah analisis data dapat dilihat sebagai berikut:

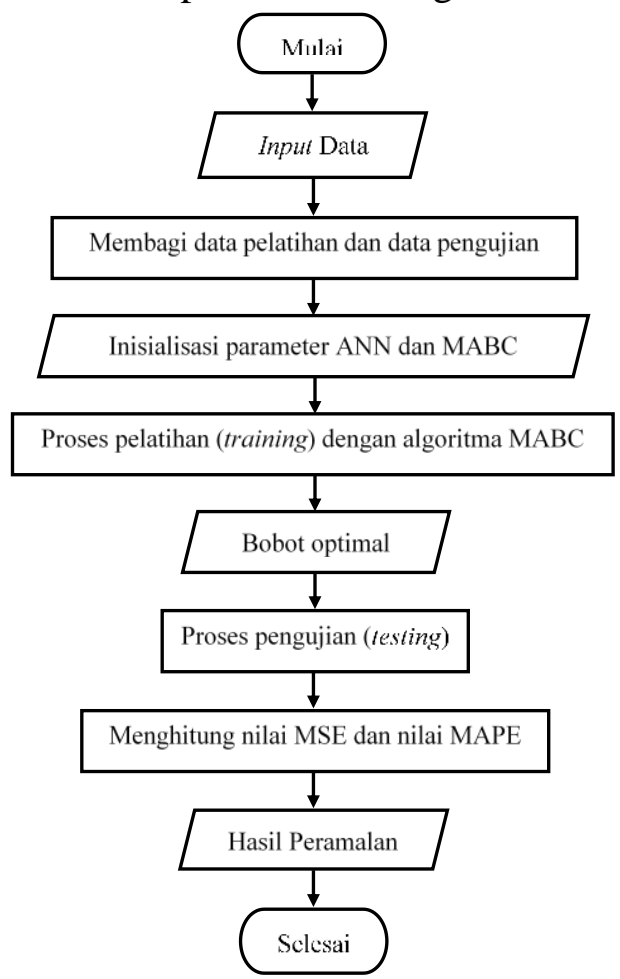

Langkah-langkah proses pelatihan (training) menggunakan algoritma MABC dapat dilihat sebagai berikut:
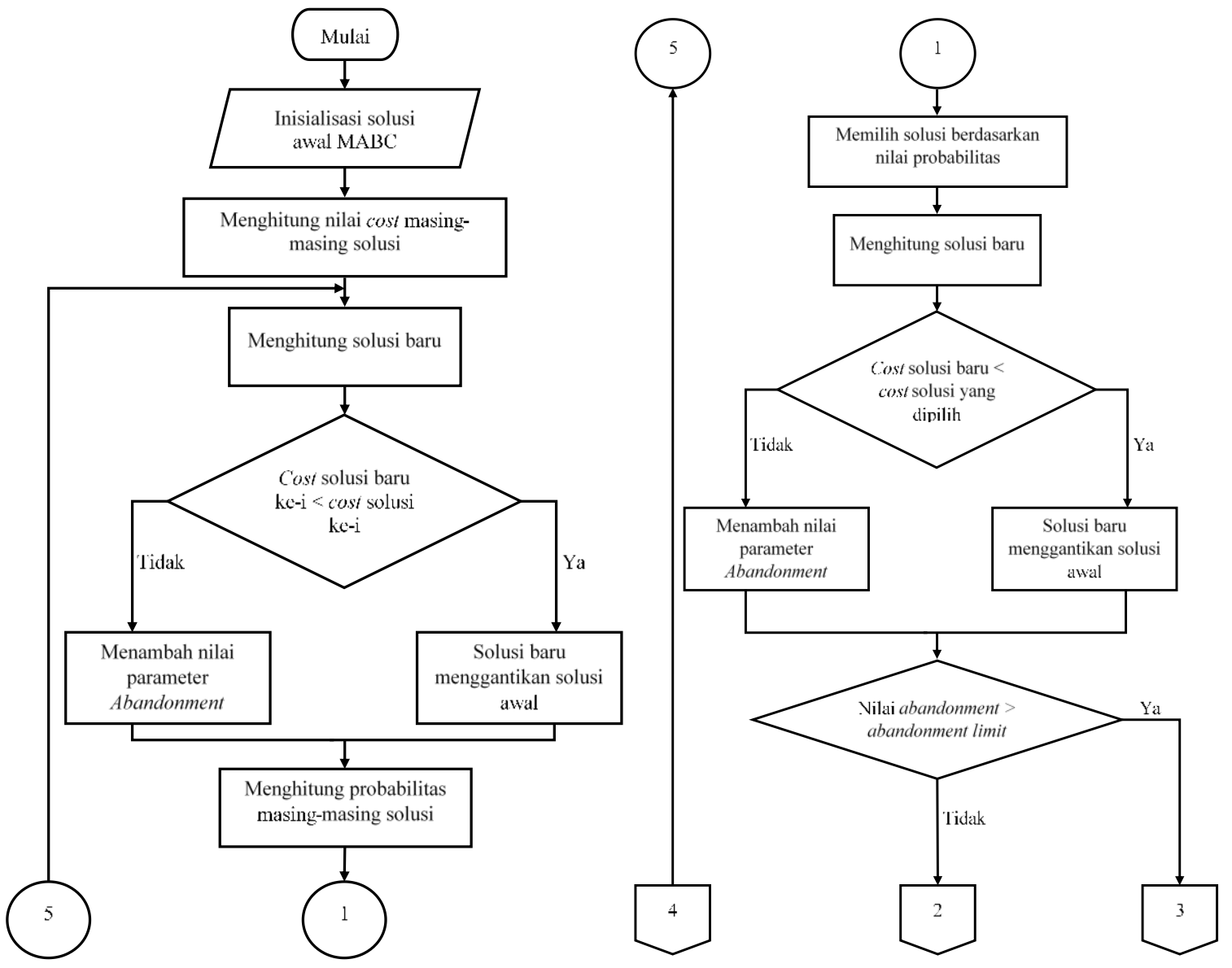


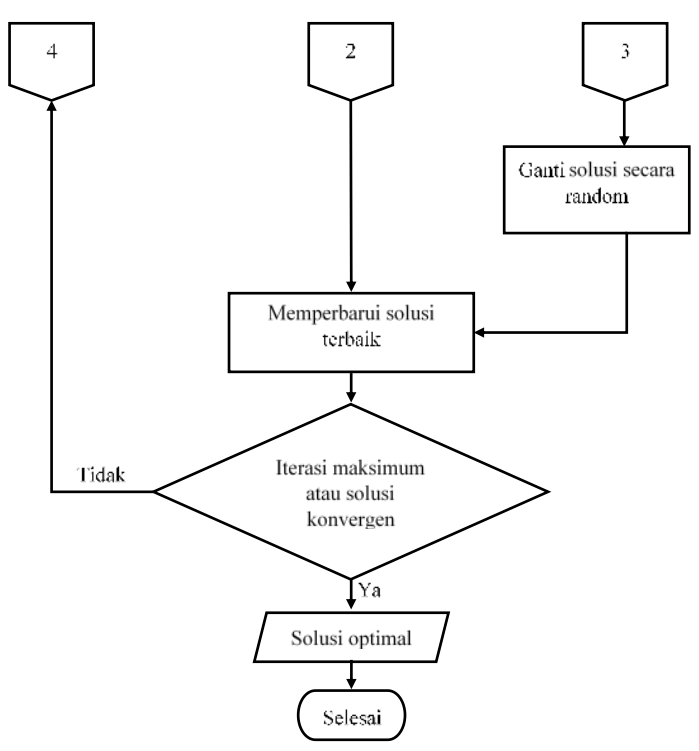

\section{HASIL DAN PEMBAHASAN}

\subsection{Menentukan Input}

Penentuan jumlah variabel input jaringan dilakukan dengan mempertimbangkan PACF. Input jaringan yang akan digunakan adalah lag-lag yang signifikan. Hal ini dikarenakan hubungan antar data dipengaruhi oleh data periode-periode sebelumnya. Setelah diketahui lag-lag yang signifikan, penentuan input menggunakan metode kombinasi trial and error jika terdapat dua atau lebih lag yang signifikan. Kemudian dilihat nilai MSE dan MAPE yang terkecil untuk dijadikan sebagai model terbaik. Plot PACF dari data harga 1 keping Bitcoin terhadap Rupiah dapat dilihat pada Gambar 1.

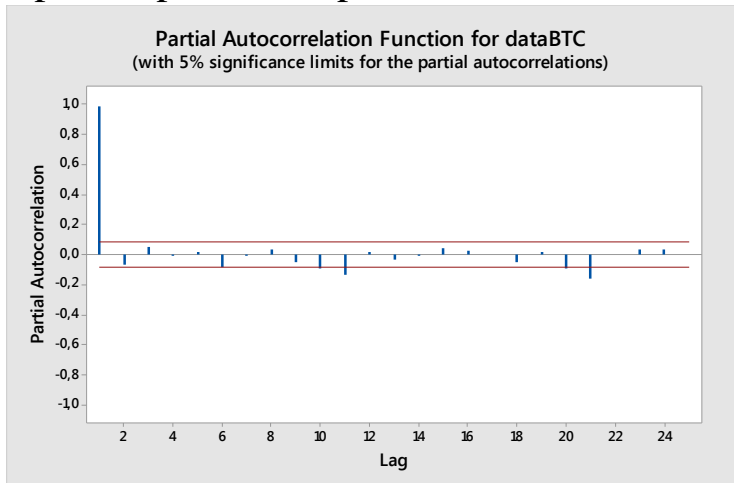

Gambar 1. Plot ACF Data Harga 1 Keping Bitcoin terhadap Rupiah

Berdasarkan Gambar 1, lag yang signifikan adalah lag 1, lag 10, lag 11, dan lag 21. Variabel-variabel yang akan dijadikan komponen input yaitu kombinasi data lag 1, lag 10, lag 11, dan lag 21. Kombinasi dimulai dari 1 variabel input sampai 5 variabel input yang kemudian dicari nilai MSE dan MAPE terkecil. Jaringan yang dibangun terdiri dari target adalah $x_{t}$ dan input adalah kombinasi dari $x_{t-1}, x_{t-10}, x_{t-11}$, dan $x_{t-21}$.

\subsection{Proses Pelatihan}

Berdasarkan hasil pelatihan pada masing-masing arsitektur jaringan, didapatkan hasil pelatihan terbaik pada Tabel 1 . 
Tabel 1. Hasil Pelatihan Terbaik untuk masing-masing Arsitektur Jaringan

\begin{tabular}{rccc}
\multicolumn{1}{c}{ Input } & $\begin{array}{c}\text { Unit Hidden } \\
\text { Layer }\end{array}$ & MSE & MAPE \\
\hline$x_{t-1}$ & 3 & $6,06 \times 10^{13}$ & $3,26 \%$ \\
$x_{t-1}, x_{t-10}$ & 2 & $6,28 \times 10^{13}$ & $3,77 \%$ \\
$x_{t-1}, x_{t-11}$ & 5 & $6,09 \times 10^{13}$ & $3,31 \%$ \\
$x_{t-1}, x_{t-21}$ & 2 & $5,85 \times 10^{13}$ & $3,19 \%$ \\
$x_{t-1}, x_{t-10}, x_{t-11}$ & 2 & $6,61 \times 10^{13}$ & $3,68 \%$ \\
$x_{t-1}, x_{t-10}, x_{t-21}$ & 5 & $6,14 \times 10^{13}$ & $3,62 \%$ \\
$x_{t-1}, x_{t-11}, x_{t-21}$ & 4 & $6,37 \times 10^{13}$ & $3,64 \%$ \\
$x_{t-1}, x_{t-11}, x_{t-11}, x_{t-21}$ & 2 & $6,28 \times 10^{13}$ & $3,82 \%$ \\
\hline
\end{tabular}

\subsection{Proses Pengujian}

Setelah dilakukan proses pelatihan selanjutnya adalah proses pengujian. Proses pengujian dilakukan pada masing-masing arsitektur jaringan terbaik. Hasil pengujian dapat dilihat pada Tabel 2.

Tabel 2. Hasil pengujian untuk masing-masing Arsitektur Jaringan Terbaik

\begin{tabular}{rcrr}
\multicolumn{1}{c}{ Input } & $\begin{array}{c}\text { Unit Hidden } \\
\text { Layer }\end{array}$ & \multicolumn{1}{c}{ MSE } & MAPE \\
\hline$x_{t-1}$ & 3 & $6,62 \times 10^{12}$ & $2,47 \%$ \\
$x_{t-1}, x_{t-10}$ & 2 & $4,97 \times 10^{12}$ & $2,26 \%$ \\
$x_{t-1}, x_{t-11}$ & 5 & $5,52 \times 10^{12}$ & $2,34 \%$ \\
$x_{t-1}, x_{t-21}$ & 2 & $6,06 \times 10^{12}$ & $2,49 \%$ \\
$x_{t-1}, x_{t-10}, x_{t-11}$ & 2 & $5,88 \times 10^{12}$ & $2,40 \%$ \\
$x_{t-1}, x_{t-10}, x_{t-21}$ & 5 & $11,37 \times 10^{12}$ & $3,65 \%$ \\
$x_{t-1}, x_{t-11}, x_{t-21}$ & 4 & $6,42 \times 10^{12}$ & $2,64 \%$ \\
$x_{t-1}, x_{t-11}, x_{t-11}, x_{t-21}$ & 2 & $9,42 \times 10^{12}$ & $3,36 \%$ \\
\hline
\end{tabular}

Berdasarkan Tabel 2 dapat dilihat bahwa hasil pengujian jaringan yang terbaik adalah arsitektur jaringan dengan 2 variabel input $x_{t-1}$ dan $x_{t-10}$ dengan jumlah unit hidden layer sebanyak 2 neuron dengan nilai MAPE sebesar 2,26\%.

\subsection{Penentuan Model}

Berdasarkan hasil pelatihan dan pengujian jaringan, arsitektur model ANN dengan metode pembelajaran MABC yang terbaik dibangun menggunakan 2 unit hidden layer dengan 2 input layer yaitu data $x_{t-1}$ dan $x_{t-10}$ dengan 1 output layer yaitu data $x_{t}$.

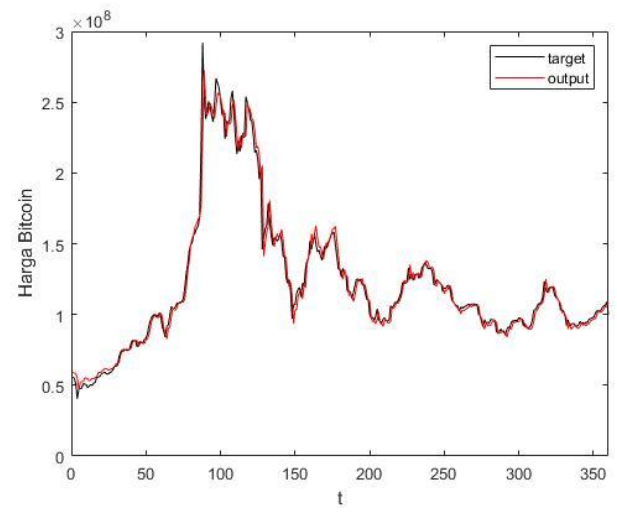

Gambar 2. Plot pelatihan Model Terbaik

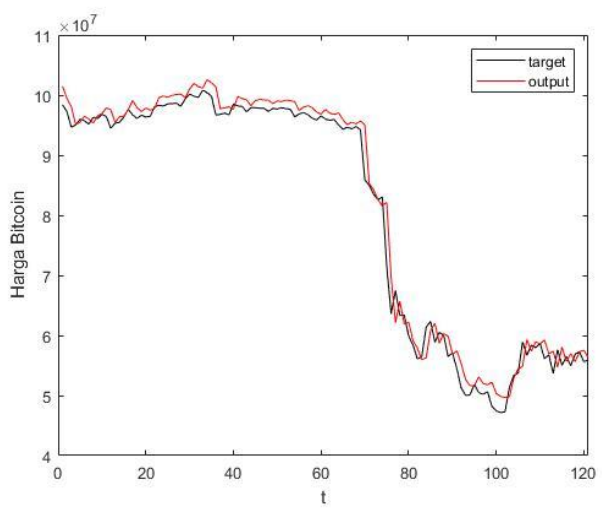

Gambar 3. Plot pengujian Model Terbaik 
Berdasarkan Gambar 2 dan Gambar 3 dapat diketahui bahwa pada proses pelatihan dan proses pengujian menghasilkan hasil prediksi cukup akurat yang ditunjukkan dengan dekatnya output (hasil prediksi) dari model yang dibentuk dengan target (data aktual).

\subsection{Pe ramalan}

Hasil peramalan pada 7 periode ke depan dimulai dari 5 Januari 2019 dapat dilihat pada Tabel 3.

Tabel 3. Hasil Peramalan Harga 1 Keping Bitcoin terhadap Rupiah tanggal

5 Januari 2019 - 11 Januari 2019

\begin{tabular}{lcc}
\hline \multicolumn{1}{c}{ Periode } & Hasil Peramalan & Aktual \\
\hline 5 Januari 2019 & 56.684 .876 & 55.557 .000 \\
6 Januari 2019 & 57.457 .569 & 57.968 .000 \\
7 Januari 2019 & 54.627 .029 & 57.315 .000 \\
8 Januari 2019 & 58.578 .575 & 57.519 .000 \\
9 Januari 2019 & 59.032 .983 & 57.376 .000 \\
10 Januari 2019 & 59.491 .395 & 52.405 .000 \\
11 Januari 2019 & 59.839 .707 & 53.190 .000
\end{tabular}

Berdasarkan Tabel 10 dapat dihitung nilai MAPE hasil peramalan sebagai berikut:

$$
\begin{aligned}
\text { MAPE } & =\frac{1}{n} \sum\left|\frac{A_{t}-F_{t}}{A_{t}}\right| \times 100 \% \\
& =\frac{1}{7}\left(\frac{409.450}{55.557 .000}+\frac{662.355}{57.968 .000}+\cdots+\frac{1.626 .410}{53.190 .000}\right) \times 100 \%=2,66 \%
\end{aligned}
$$

Didapatkan nilai MAPE sebesar 2,66\% yang dapat dikatakan keakuratan hasil peramalan akurat karena nilai MAPE yang kurang dari $10 \%$.

\section{KESIMPULAN}

Berdasarkan hasil dan pembahasan dari peramalan harga Bitcoin terhadap Rupiah menggunakan Artificial Neural Network dengan optimasi Modified Artificial Bee Colony, dapat diambil kesimpulan sebagai berikut:

1. Model terbaik yang diperoleh dari proses pelatihan dan proses pengujian adalah arsitektur ANN dengan 2 input layer yaitu $x_{t-1}$ dan $x_{t-10}$ dengan jumlah unit hidden layer sebanyak 2 neuron dan 1 output layer yaitu $x_{t}$ berdasarkan nilai MAPE yang terkecil.

2. Hasil proses pelatihan dan proses pengujian menunjukkan bahwa hasil peramalan memberikan akurasi yang baik ditunjukkan dengan plot hasil pelatihan dan pengujian pada Gambar 2 dan Gambar 3 yang menunjukkan hasil prediksi dekat dengan data aktualnya dan nilai MAPE yang di bawah $10 \%$.

\section{DAFTAR PUSTAKA}

Karaboga, D. \& Akay, B., 2009. A Comparative Study of Artificial Bee Colony Algorithm. Applied Mathematics and Computation, Volume 214, pp. 108-132.

Makridakis, S., Wheelwright, S. C. \& McGree, V. E., 1999. Metode dan aplikasi permalan. Edisi Kedua Jilid Satu, Alih Bahasa Hari Suminto ed. Jakarta: Binarupa Aksara.

Shahrudin, M. S. \& Mahmudin, 2014. Experiment on Modified Artificial Bee Colony for Better Global Optimization. Advanced in Computer Science and Its Applications, Lecture Notes in Electrical Engineering, Volume 279, pp. 735-741.

Soejoeti, Z., 1987. Analisis Runtun Waktu. Jakarta: Karunika.

Subagyo, P., 1986. Forcesting Konsep dan Aplikasi. Yogyakarta: BPEE UGM.

Wardah, S. \& Iskandar, 2016. Analisis Peramalan Penjualan Produk Keripik Pisang Kemasan Bungkus. Jurnal Teknik Industri, Vol. XI(3), pp. 135-142. 
Warsito, B., 2009. Kapita Selekta Statistika Neural Network. Semarang: BP UNDIP. Wijaya, D. A., 2018. Bitcoin Mining dan Cryptocurrency lainnya. Jakarta: Jasakom. 